\title{
REKAYASA PERANGKAT LUNAK UNTUK JASA PINDAH BERBASIS WEB
}

\author{
Erlin Elisa ${ }^{1}$, Nurul Azwanti ${ }^{2}$ \\ Teknik dan Komputer, Universitas Putera Batam ${ }^{\mathbf{1 , 2}}$ \\ erlin.Elisa@puterabatam.ac.id ${ }^{1}$, Nurul.Azwanti@ puterabatam.ac.id ${ }^{2}$ \\ DOI: http://dx.doi.org/10.31869/rtj.v2i2.1430
}

\begin{abstract}
Perkembangan teknologi dijaman sekarang ini sangatlah canggih dan pesat. Hal ini dapat dibuktikan dengan banyaknya inovasi dimasa ini, dengan yang sederhana maupun yang menghebohkan dunia, begitu juga dengan pengembangan perangkat lunak sebelumnya telah melihatkan hubungan antara kebutuhan dan arsitektur. Kota Batam yang berada di Kepri memiliki pertumbuhan penduduk paling tinggi dalam satu dasawarsa terakhir yaitu 7,70 persen per tahun, Jumlah penduduk di Batam berdasarkan Sensus Penduduk 2010-2015 sebanyak 1.061.375 orang, mengalami peningkatkan pesat dibanding 10 tahun sebelumnya yang hanya mencapai 455.103 orang. Dengan demikian perpindahan penduduk tentu semakin banyak mulai dari mereka yang datang pertama ke kota Batam ini awalnya tinggal dirumah sewaan kemudian dengan berjalannya waktu mereka telah memiliki rumah sendiri atau bisa jadi pindah dari rumah sewa satu ke yang lainnya, perpindahan ini kadang menjadi kendala bagi mereka yang disibukan dengan rutinitas pekerjaan sehari-hari karena jadwal pekerjaan yang padat ditambah waktu istirahat yang kurang, sehingga apabila mereka pindah rumah sulit untuk merencanakan secepat mungkin karena mulai dari mencari jasa angkutan, packing barang hingga merapikan ditempat yang baru sangat melelahkan bagi mereka, maka penelitian ini membuat sebuah rekayasa perangkat lunak untuk jasa pindah berbasis web yang nantinya dapat dimanfaatkan untuk mencari jasa untuk pindahan termasuk dengan fasilitas -fasailitas lain yang berguna pada saat pindahan tersebut, sistem ini akan dibangun dan dirancang dengan UML, pemrograman PHP 5 dan database MySql.hasil dari penelitian ini memudahkan para pencari jasa angkutan pindahan termasuk jasa lainnya yang berhubungan dengan pindah rumah,kantor dan angkutan barang bekas.
\end{abstract}

Keywords: Jasa Pindah, Sistem, Rekayasa ,Website

\section{PENDAHULUAN}

Pengembangan perangkat lunak sebelumnya telah melihatkan hubungan antara kebutuhan dan arsitektur. Dimana kebutuhan yang diperoleh digunakan oleh arsitek perangkat lunak untuk mengembangkan suatu arsitektur yang memenuhi kebutuhan yang diharapkan. Hal ini cenderung mengarahkan terciptanya desain yang mempunyai inovasi yang baik dalam mengimplementasikan setiap sistem yang baru, tentunya peranan kebutuhan ini dapat memberikan pengaruh yang sangat penting untuk memberikan pemahaman kepada pemilik dan pengguna perangkat lunak ketika akan membangun suatu perangkat lunak (Surya, 2017). Kebutuhan akan perangkat lunak ini dapat dilihat dari berkembangnya penggunaan internet dikalangan masyarakat dari berbagai kalangan, keinginan untuk melakukan dengan praktis dan cepat sudah menjadi budaya bagi masyarakat saat sekarang hal ini dapat dilihat dari ketersediaan berbagai aplikasi atau situs yang di sajikan dunia peselancaran internet.

Kota Batam yang berada di Kepri memiliki pertumbuhan penduduk paling tinggi dalam satu dasawarsa terakhir yaitu 7,70 perse per tahun, Jumlah penduduk di Batam berdasarkan Sensus Penduduk 2010-2015 sebanyak 1.061 .375 orang, meningkat pesat dibanding 10 tahun sebelumnya yang hanya mencapai 455.103 orang, apalagi hingga tahun 2018 penduduk kota Batam apabila kita lihat dari kasat mata sudah semakin padat saja. Dengan demikian perpindahan penduduk tentu semakin banyak mulai dari mereka yang datang pertama ke kota Batam ini hanya tinggal pada rumah sewaan, kemudian dengan berjalannya waktu mereka telah memiliki rumah sendiri atau bisa jadi pindah dari rumah sewa satu ke yang lainnya.

Peristiwa perpindahan ini kadang menjadi kendala bagi mereka yang disibukan dengan rutinitas pekerjaan sehari-hari, karena rata-rata dari jumlah penduduk dikota batam 
bermata pencarian sebagai pekerja di PT, galangan kapal sampai yang bekerja dibidang pendidikan dan pemerintahan oleh karena itu karena jadwal pekerjaan yang padat ditambah waktu istirahat yang kurang, sehingga kegiatan pindah rumah kerumah baru atau rumah sewaan lain sulit bagi mereka untuk merencanakan secepat mungkin, apalagi dengan kondisi pemilik rumah sewaan menyuruh mereka untuk segera pindah, permasalahan yang ditemui akibat kejadian ini yaitu mulai dari mencari jasa angkutan, packing barang-barang hingga merapikan ditempat yang baru sangat melelahkan dan memakan waktu sehingga ada yang harus libur bekerja untuk melakukannya.

Dari permasalahan diatas maka peneliti ingin membuat sebuah rekayasa perangkat lunak untuk jasa pindah berbasis web, aplikasi web ini akan menyediakan fitur-fitur tentang sarana yang dibutuhkan untuk pindahan seperti mulai dari jasa angkutan, packing, hingga penyusunan barang ditempat yang baru. Rekayasa merupakan penerapan ilmu dan teknologi untuk menyelesaikan permasalahan manusia. Sedangkan rekayasa perangkat lunak atau RPL atau Software engineering adalah satu bidang yang mendalami cara-cara pengembangan perangkat lunak termasuk pembuatan, pemeliharaan, manajemen organisasi pengembangan perangkat lunak, dan sebagainya (Yehendra \& Yulianto, 2015).

\section{METODE PENELITIAN}

Metode penelitian ini akan menggunakan metode pengembangan perangkat lunak yang telah dipilih, yakni menggunakan model waterfall. Untuk lebih jelas dapat dilihat pada gambar berikut ini.

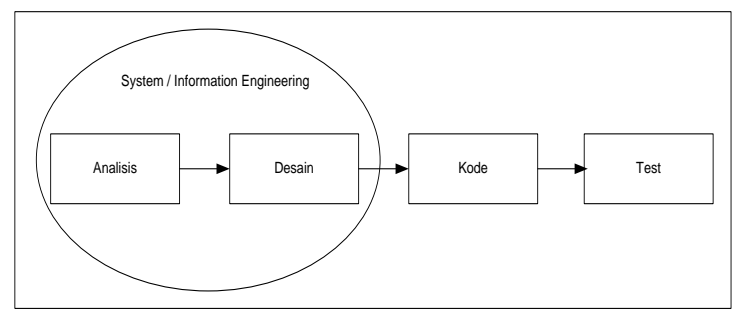

Gambar 1. SDLC Model Waterfall

\section{HASIL DAN PEMBAHASAN}

Konsep Rekayasa Perangkat Lunak

Rekayasa perangkat lunak merupakan salah satu disiplin rekayasa yang memberikan hasil abstrak. Kondisi ini berbeda dengan disiplin rekayasa yang seperti elektronika mesin maupun sipil dimana hasil proses rekayasa memberikan bentuk nyata. Pengukuran volume sebuah hasil rekayasa yang abstrak menjadi tidak semudah pengukuran volume hasil rekayasa yang memberikan hasil konkret. Pengukuran volume pekerjaan rekayasa perangkat lunak yang abstrak hanya didasarkan kepada kegunaan dari hasil rekayasa. Volume dalam ukuran byte panjangnya kode program terkadang tidak linier dengan kegunaan dari hasil rekayasa perangkat lunak (Setyanto, 2010).

Menurut IEEE, definisi rekayasa perangkat lunak adalah aplikasi dari sebuah pendekatan disiplin dan sistematis kepada pengembangan, operasi, dan pemeliharaan perangkat lunak yaitu aplikasi dari rekayasa perangkat lunak. Model proses untuk rekayasa perangkat lunak dipilih berdasarkan sifat aplikasi dan proyeknya, metode dan alat-alat bantu yang akan dipakai, kontrol, serta penyampaian yang dibutuhkan. Model-model proses untuk software engineering seperti model sekuensial linier atau waterfall model, model prototipe, model RAD, model inkremental, model spiral, model pengembangan terpadu, model metode formal, dan model teknik generasi keempat (Binarso, Sarwoko, \& Bahtiar, 2012).

\section{Website}

Website atau situs juga dapat diartikan sebagai kumpulan halaman yang menampilkan informasi data teks, data gambar diam atau gerak, data animasi, suara, video dan atau gabungan dari semuanya, baik yang bersifat statis maupun dinamis yang membentuk satu rangkaian bangunan yang saling terkait dimana masing-masing dihubungkan dengan jaringanjaringan halaman (hyperlink). Bersifat statis apabila isi informasi website tetap, jarang berubah, dan isi informasinya searah hanya dari pemilik website. Bersifat dinamis apabila isi informasi website selalu berubah-ubah, dan isi informasinya interaktif dua arah berasal dari pemilik serta pengguna website (Nurmi, 2015).

Website juga merupakan kumpulan halaman web yang saling terhubung dan file-file yang saling terkait. Web terdiri dari page atau halaman, dan kumpulan halaman yang dinamakan homepage. Homepage berada pada posisi teratas, dengan halaman-halaman terkait 
berada di bawahnya. Biasanya setiap halaman di bawah homepage disebut child page, yang berisi hyperlink ke halaman lain dalam web (Ferdika \& Kuswara, 2017).

\section{UML (Unified Modeling Language).}

UML (Unifield Modeling Language) adalah bahasa yang digunakan untuk memodelkan perangkat lunak yangakan dibuat dan perlu adanya standarisasi agar orang diberbagai negara dapat mengerti pemodelan perangkat lunak (Mulayana \& Gustina, 2016). Unifed Modeling Language (UML) adalah keluarga notasi grafis yang didukung oleh meta-model tunggal, yang membantu pendekskripsian dan desain sistem perangkat lunak, khususnya sistem yang dibangun menggunakan pemrograman berorientasi objek (Isa \& Hartawan, 2017).

\section{Usecase Diagram}

Usecase diagram digunakan untuk menggambarkan sistem dari sudut pandang pengguna sistem tersebut (user). Sehingga pembuatan usecase diagram lebih dititik beratkan pada fungsionalitas yang ada pada sistem, bukan berdasarkan alur atau urutan kejadian. Sebuah usecase diagram mempresentasikan sebuah interaksi antara aktor dengan sistem.

\section{Class Diagram}

Class diagram adalah spesifikasi yang akan menghasilkan objek dan merupakan inti dari pengembangan dan desain berorientasi objek. Class menggambarkan keadaan (atribut atau properti) suatu sistem, sekaligus menawarkan layanan untuk memanipulasi keadaan tersebut (metode atau fungsi). Kelas memiliki tiga area pokok:
a. Nama (Class Name)
b. Atribut
c. Metode (Operation)

3. Sequence Diagram

Menggambarkan interaksi antara sejumlah objek dalam urutan waktu. Kegunananya untuk menunjukan rangkaian pesan yang dikirim antara objek juga interaksi antar objek yang terjadi pada titik tertentu dalam eksekusi sistem.
4. Activity Diagram

Menggambarkan rangkaian aliran dari aktivitas, digunakan untuk mendeskripsikan aktifitas yang dibentuk dalam suatu operasi sehingga dapat juga digunakan untuk aktifitas lainnya. Diagram ini sangat mirip dengan flowchart karena memodelkan workflow dari suatu aktifitas ke aktifitas yang lainnya, atau dari aktifitas ke status. Pembuatan activity diagram pada awal pemodelan proses dapat membantu memahami keseluruhan proses. Activity diagram juga digunakan untuk menggambarkan interaksi antara beberapa use case (Isa \& Hartawan, 2017).

\section{PHP (Hipertext Preprocessor).}

PHP adalah akronim dari Hipertext Preprocessor, yaitu suatu bahasa berbasis kode-kode (script) yang digunakan untuk mengolah suatu data dan mengirimkannya kembali ke web browser menjadi kode HTML.Kode PHP mempunyai ciri-ciri khusus, yaitu (Septa, Hamzah, \& Andayati, 2014).

1. Hanya dapat dijalankan menggunakan web server, missal: Apache dan Xampp.

2. Kode PHP diletakan dan dijalankan di web server.

3. Kode PHP dapat digunakan untuk mengakses basis data, seperti: MySQL, postgreSQL, Oracle, dan lain-lain.

4. Merupakan software yang bersifat open source.

5. Gratis untuk di-download dan digunakan.

6. Memiliki sifat multiplatform, artinya dapat dijalankan menggunakan sistem operasi apapun, seperti: Linux, Windows, dan lainlain.

My SQL

MySQL adalah sistem manajemen relasi basis data yang bersifat terbuka atau open source, open source adalah dapat digunakan oleh siapa saja, baik versi kode program aslinya maupun versi binernya dan bisa digunakan secara gratis baik untuk dimodifikasi sesuasi dengan kebutuhan seseorang maupun sebagai suatu program aplikasi komputer. Kelebihan lain dari MySQL adalah menggunakan bahasa query standart yang dimiliki SQL (Structure Query Language). SQL adalah suatu bahasa permintaan yang terstruktur yang telah distandarkan untuk semua program pengakses 
Vol. 2 No.2 Juni 2019

http://jurnal.umsb.ac.id/index.php/RANGTEKNIKJOURNAL

database seperti Oracle, PostGree SQL, SQL

Server, dan lain - lain (Apriliani \& Sholeh, 2016).

\section{Perancangan Sistem}

Setelah dilakukan tahap analisis sistem pada sistem yang selama ini digunakan oleh masyarakat selama ini khususnya pada objek penelitian yaitu untuk mencari sebuah jasa pindahan bagi mereka dengan menelpon dan bertanya-tanya pada tetangga tentang dimana ada angkutan untuk pindahan, kemudian tahap selanjutnya adalah perancangan sistem yang sesuai dengan kebutuhan guna memperbaiki kelemahan yang ada. Perancangan sistem menggambarkan kerangka sistem yang dibangun dengan bantuan alat perancangan. Tujuannya adalah untuk mempermudah user dalam memahami sistem yang baru.website atau sistem yang akan di rancang adalah jasa bantu pindah.

Perancangan ini menggunakan Unified Modelling Language (UML) untuk menjelaskan prosedur, proses dan pemodelan untuk menjelaskan sistem yang dirancang. Adapun perancangan UML yang digunakan adalah sebagai berikut.

\section{Use Case Diagram}

Use case diagram menjelaskan aktor yang terlibat dan interaksi-interaksi yang dilakukan pada sistem. Use case diagram dari bantupindah.com yang dirancang dapat dilihat pada gambar berikut.

a. Usecase Diagram Daftar Anggota atau Calon Anggota

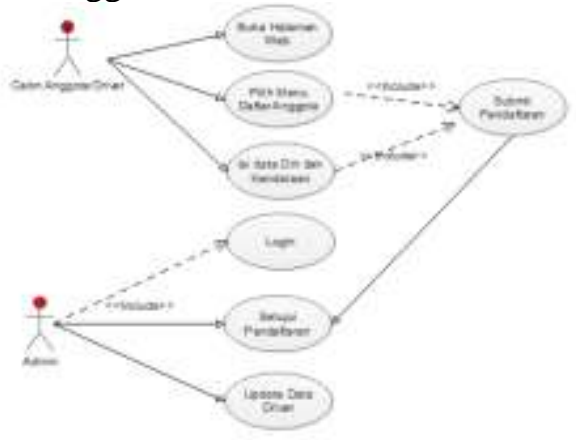

Gambar 2. Usecase Diagram Daftar Calon Anggota b. Usecase Diagram Pelanggan

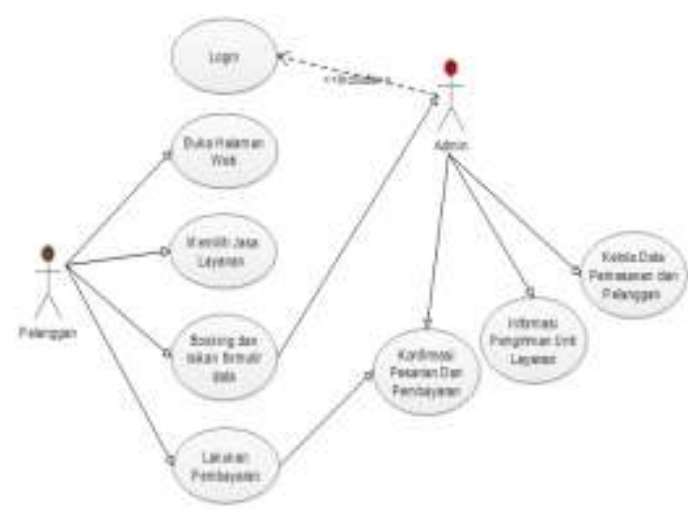

Gambar 3. Usecase Diagram Pelanggan

\section{Activity Diagram}

Acivity diagram menjelaskan tentang workflow (aliran kerja) dari sistem yang berjalan pada perancangan sistem bantupindah.com berbasis web. Aktivitas yang terjadi pada sistem ini dapat dilihat pada gambar-gambar di bawah ini:

a. Activity Diagram Pendaftaran Anggota

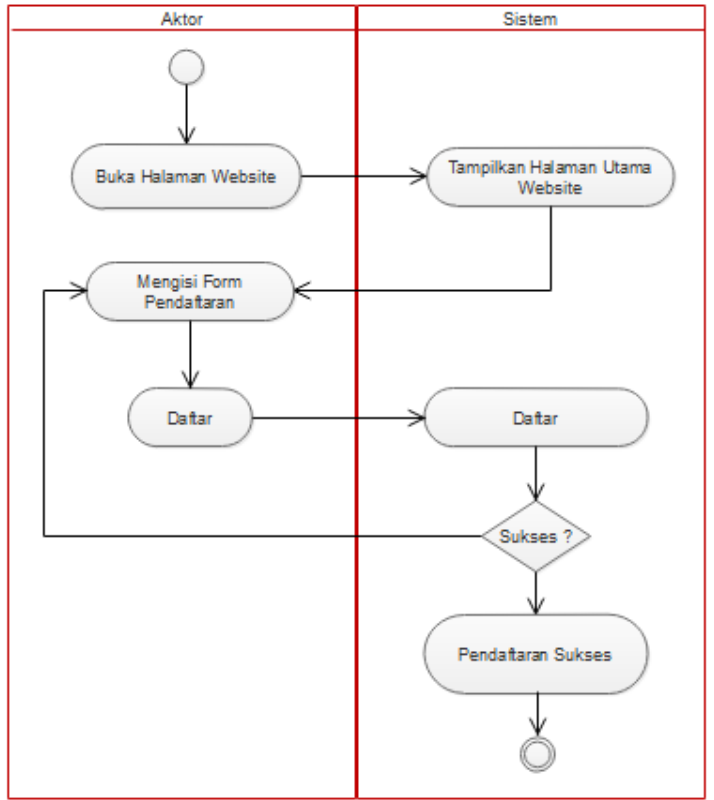

Gambar 4. Activity Diagram Daftar Anggota

Pada gambar 4 menjelaskan aktifitas aliran kerja calon penyedia jasa angkutan atau anggota terhadap sistem dimana untuk calon penyedia wajib mengisi form pendaftaran terlebih dalulu baik itu data diri dan kendaraan yang akan di daftarkan kemudian tekan atauk 
Vol. 2 No.2 Juni 2019

http://jurnal.umsb.ac.id/index.php/RANGTEKNIKJOURNAL

klik tombol daftar pada sistem, apabila data yang dimasukan telah lengkap maka pendaftaran sukses dan apabila data yang diisikan masih salah maka sistem akan mengatakan untuk mengisi ulang dengan data yang benar.

b. Activity Diagram Login

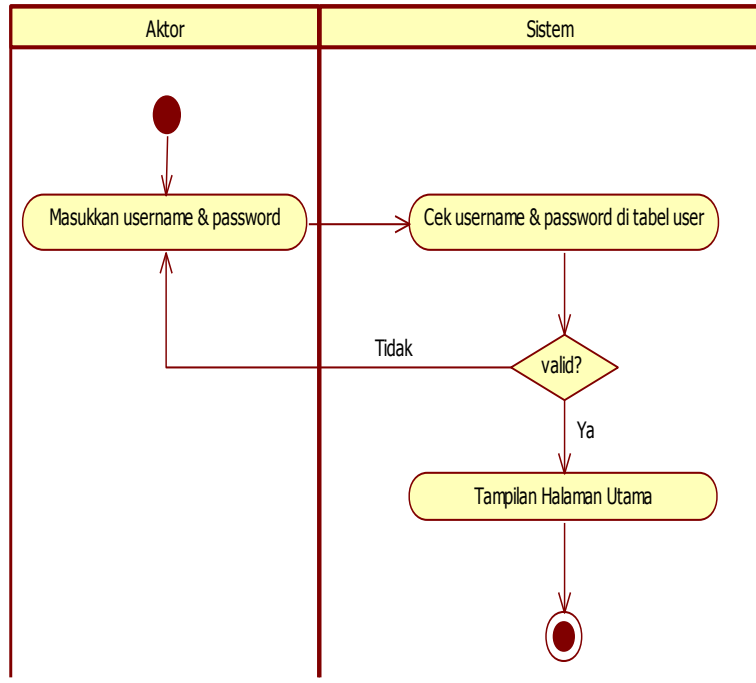

Gambar 5. Activity Diagram Login

Pada gambar 5 menjelaskan mengenai aliran kerja login aktor yaitu admin pada sistem terlebih dahulu harus masuk dengan username dan password yang telah diberikan. Sistem akan melakukan pengecekan pada database, jika username dan password tidak sesuai maka login gagal. Jika sesuai, maka tampilan halaman utama akan muncul.

c. Activity Diagram Daftar Anggota

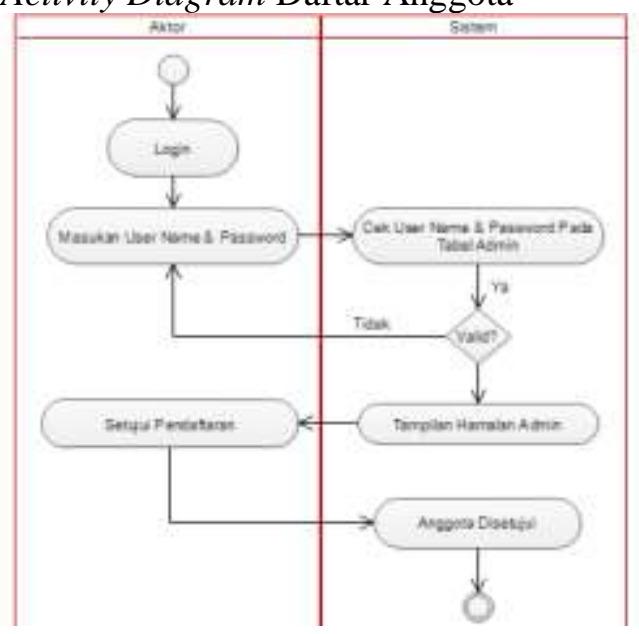

Gambar 6. Activity Diagram Menyetujui Pendaftaran Anggota
Pada gambar 6 dijelaskan aliran kerja dari aktifitas admin untuk menyetujui pendaftaran calon anggota, sebelum masuk ke sistem admin harus login terlebih dahulu kemudian admin akan mengecek calon anggota yang akan mendaftarkan angkutannya, apabila telah sesuai data yang diberikan baik secara komputerisasi maupun fisik maka admin akan menyetujui, namun apabila data yang dimasukan tidak sesuai maka admin berhak untuk menolak atau mengabaikan pendaftaran dari calon anggota.

d. Activity Diagram Update Layanan Jasa

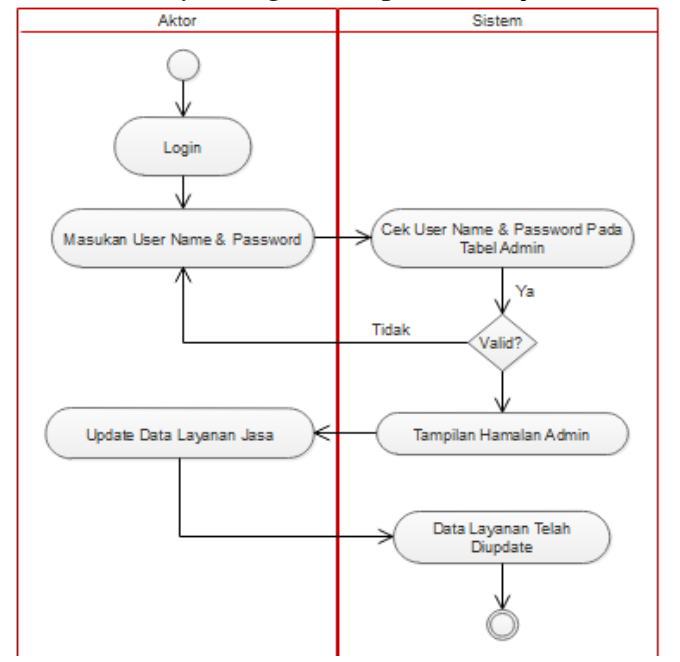

Gambar 7. Activity Diagram Update Data Layanan Jasa

Dari gambar 7 diatas dapat dijelaskan aliran kerja admin dengan sistem untuk mengupdate data layanan jasa yang disediakan termasuk unit atau armada baru yang bergabung pada sistem website bantu pindah ,data-data yang masuk dalam pendaftaran akan di update dan disimpan ke database oleh admin,agar pelanggan dapat lebih mudah mendapatkan layanan jasa pindah online ini. 


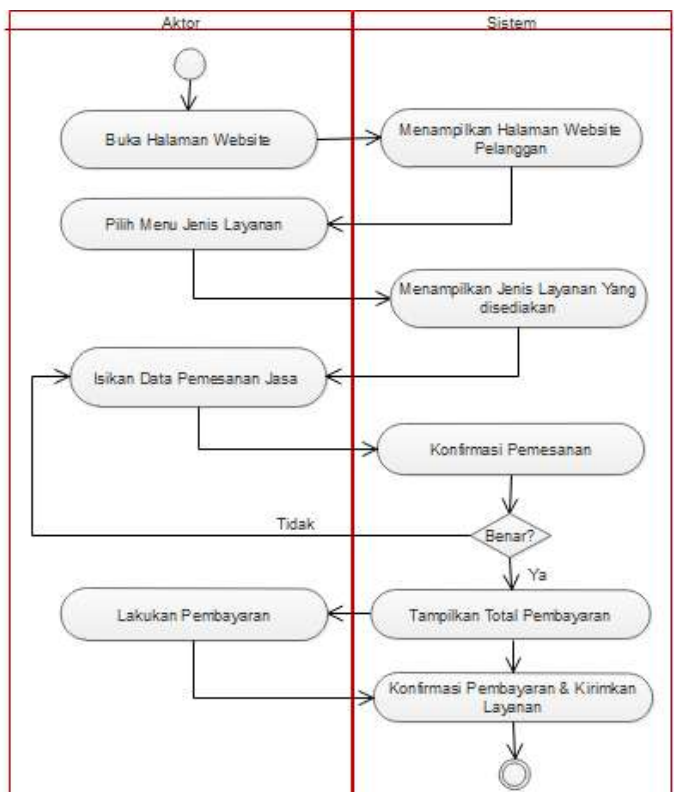

Gambar 8. Activity Diagram Layanan Bantu Pindah Untuk Pelanggan

\section{Perancangan Antar Muka}

Untuk memudahkan pengguna dalam mengoperasikan sistem yang dibangun, perlu adanya sebuah interface atau biasa disebut dengan antarmuka. Perancangan antarmuka secara umum terdiri dari perancangan struktur menu, perancangan input dan perancangan output.

1. Struktur Menu

Struktur menu pada sistem bantupindah.com dapat dilihat pada gambar berikut ini.
1. Halaman Menu Home

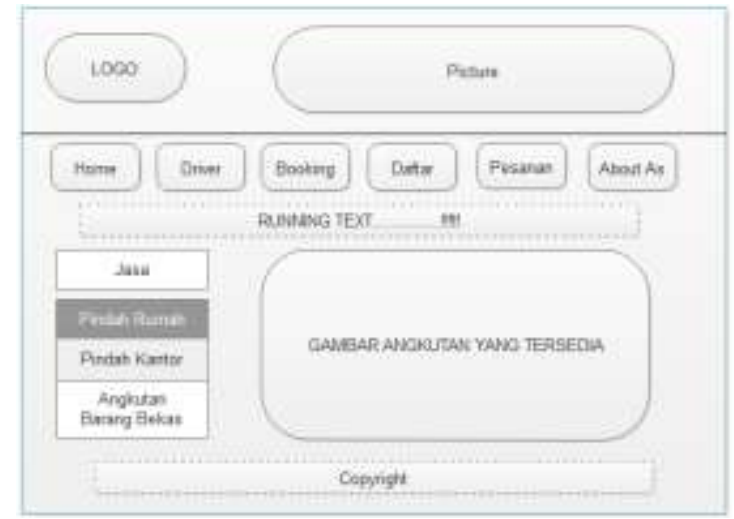

Gambar 10. Rancangan Form Menu Home

2. Halaman Menu Driver

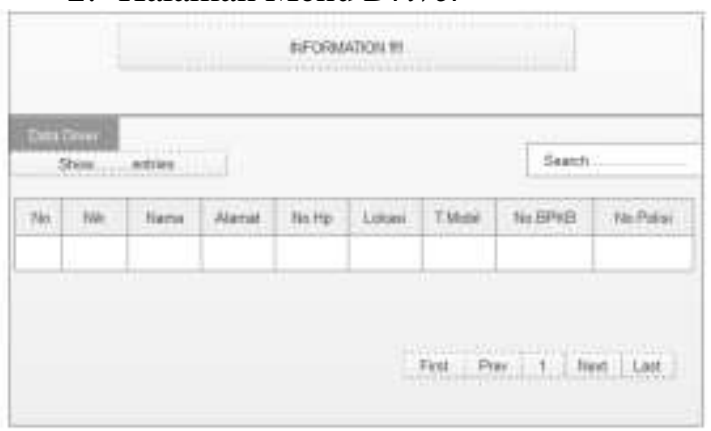

Gambar 11. Rancangan Form Menu Driver

3. Halaman Menu Booking atau Form Pemesanan Jasa

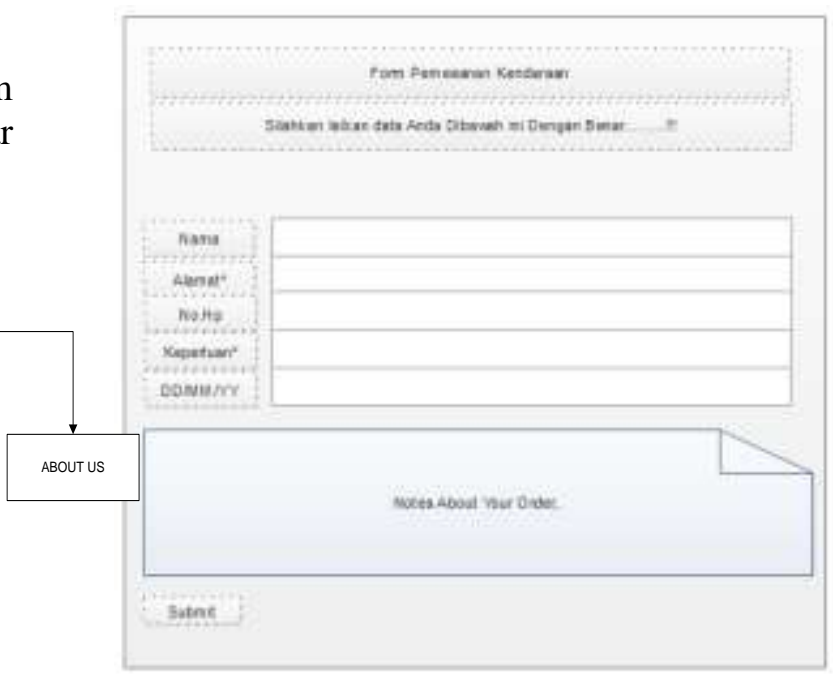

Gambar 12. Rancangan Form Pemesanan Jasa

4. Halaman Menu Form Pendaftaran Untuk Menjadi Anggota.

a. Perancangan Menu Utama 


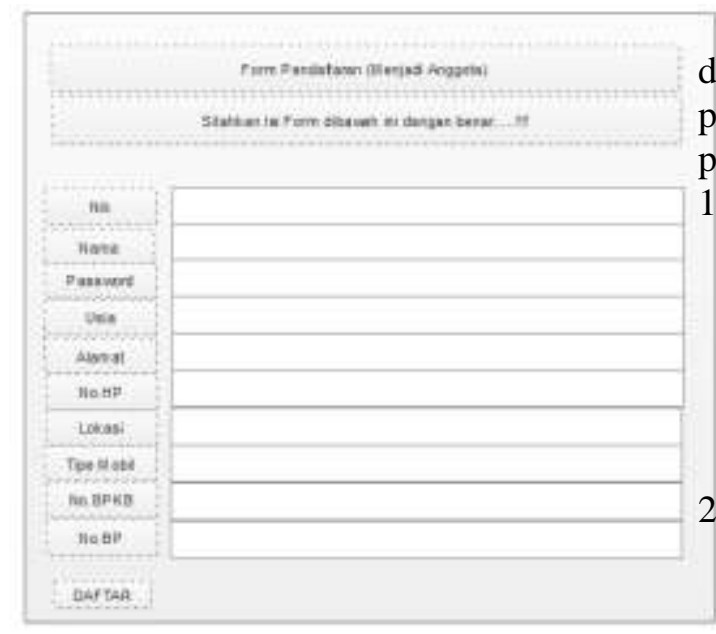

Gambar 13. Rancangan Form Pendaftaran Menjadi Anggota

5. Halaman Menu Form Login Pesanan

\section{Tampilan Layout Website}

Gambar 14. Rancangan Form Login Pesanan

Tampilan layout program website dari bantupindah.com dapat dilihat pada gambar dibawah ini.

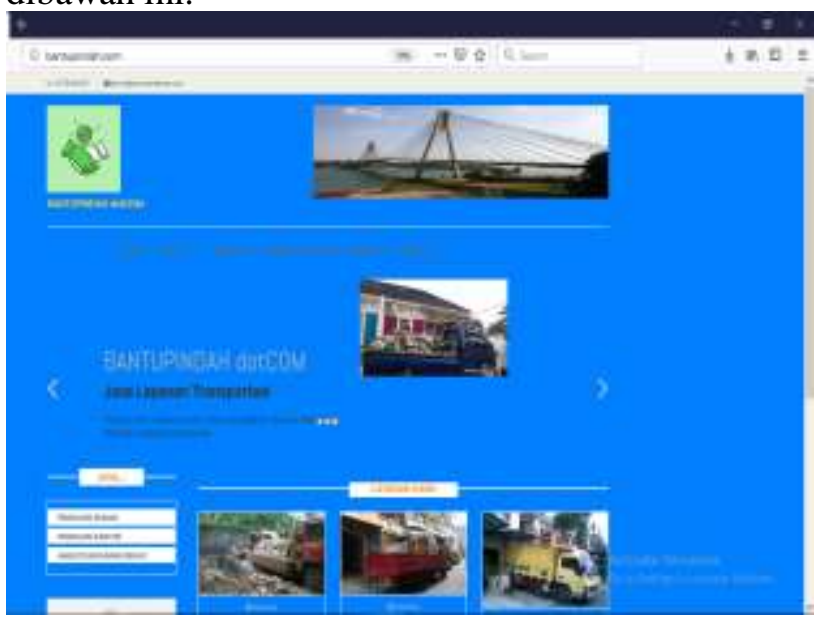

Gambar 15. Tampilan Website

Berdasarkan penelitian yang telah dilakukan untuk membangun rekayasa perangkat lunak untuk jasa pindah online maka peneliti mengambil simpulan sebagai berikut:

1. Sistem Jasa Pindah Online yang dibangun dapat membantu masyarakat dalam mencari jasa untuk melakukan pindahan tanpa harus membuang waktu karena sistem yang dibuat sangat mudah dan efektif digunakan terutama masyarakat yang memiliki tingkat kesibukan yang padat.

2. Sistem bantupindah.com akan menghemat waktu dan biaya, mulai dari pencarian angkutan karena dilakukan secara komputerisasi, begitu juga jasa yang disediakan

\section{Saran}

Dari penelitian yang telah dilakukan, terdapat masih banyak kekurangan pada sistem yang dirancang, untuk itu peneliti memberikan beberapa saran sebagai masukan pada penelitian lebih lanjut. Adapun saran dari peneliti adalah :

1. Perlu pengembangan tampilan atau interface yang lebih menarik lagi tanpa mengurangi kemudahan para pengguna sistem.

2. Perlu pengembangan sistem kedalam bentuk aplikasi mobile agar bisa di akses dimana saja dan kapan saja.

3. Perlu adanya sistem keamanan untuk menjaga privasi pengguna maupun anggota yang bergabung dengan sistem.

\section{UCAPAN TERIMAKASIH}

Terimakasi kepada peneliti ucapkan kepada civitas akademika Universitas Putera Batam dan LPPM Universitas Putera Batam yang telah membeli kemudahan dan kelancaran untuk penelitian ini,kemudian terimakasih pula kepada anggota tim peneliti yang telah bekerjasama dan pihak-pihak lainnya yang tidak bisa disebutkan satu persatu,berkat bantuan dan dukungan mereka sehinnga penelitian ini terlaksana dengan baik.

\section{DAFTAR PUSTAKA}

Anderson, J. (2015). Rancang Bangun Sistem Informasi AKuntansi Pada CV. Riau Jaya Lestari Berbasis Web, 15(2), 22-28.

Apriliani, D. R., \& Sholeh, M. (2016). Pembuatan Sistem Informasi Administrasi Bagian wakaf Berbasis Web di SD IT AL-

PENUTUP Simpulan

Khairaat Yogyakarta Dengan PHP MySql, 
3(2), 182-190.

Binarso, Y. A., Sarwoko, E. A., \& Bahtiar, N. (2012). Pembangunan sistem informasi alumni berbasis web pada program studi teknik informatika universitas diponegoro. Journal of Information and Technology, 1(1), 72-84. Retrieved from http://ejournals1.undip.ac.id/index.php/joint

Christian, A., \& Ariani, F. (2018). Rancang Bangun Sistem Informasi Peminjaman Perangkat Demo Video Conference Berbasis Web Dengan Metode Waterfall. Jurnal Pilar Nusa Mandiri, 14(1), 131136.

Click, J. J., Sistem, J., Dan, I., Informatika, M., Informasi, S., Padang, S. J., ... No, L. (2018). Jurnal J - Click, 4(2), 167-178.

Dede Wira Trise Putra, J. J. P. (2018). Perancangan Sistem Informasi Pencarian Lowongan Pekerjaan. Jurnal TEKNOIF, 6(1), $48-54$ https://doi.org/10.21063/JTIF.2018.V6.1. 48-54

Ferdika, M., \& Kuswara, H. (2017). Sistem Informasi Penjualan Berbasis Web Pada PT Era Makmur Cahaya Damai Bekasi. Information System for Educatos and Professionals. E-ISSN: 2548-3587, 1(2), 175-188. Retrieved from http://ejournalbinainsani.ac.id/index.php/ISBI/article/vie w/390/392

García, F., Pedreira, O., Piattini, M., CerdeiraPena, A., \& Penabad, M. (2017). A framework for gamification in software engineering. Journal of Systems and Software, 132, 21-40. https://doi.org/10.1016/j.jss.2017.06.021

Handayani, S. (2018). Perancangan Sistem Informasi Penjualan Berbasis ECommerce Studi Kasus Toko Kun Jakarta, 10, 182-189.

Hidayat, A. S., Saputro, M. I., \& Sukedar, T. (2018). Perancangan Ensiklopedia Mobile Flora Dan Fauna Indonesia Berbasis Android. Jurnal Teknologi Informatika \& Komputer, 4(2), 8-46. Retrieved from http://ejournal-

umht.org/index.php/tik/article/view/108

Iriadi, N., \& Rosdiana, N. (2017). Perancangan Sistem Informasi Penjualan Minuman Kemasan Berbasis Web Pada Toko Bambu Sejahtera Bekasi. Jurnal
Khatulistiwa Informatika, 5(1), 42-47. Retrieved from http://ejournal.bsi.ac.id/ejurnal/index.php/ khatulistiwa/article/view/2035/1488

Isa, I. G. T., \& Hartawan, G. P. (2017). Perancangan Aplikasi Koperasi Simpan Pinjam Berbasis Web (Studi Kasus Koperasi Mitra Setia). Jurnal Ilmiah Ilmu Ekonomi, 5, 139-151.

Kasus, S., Sains, I., \& Yogyakarta, T. A. (2017). Vol . 10 No . 1 Agustus 2017 ISSN : 1979-8415 Perancangan Sistem Pengambilan Kartu Ujian Online Menggunakan Framework Codeither Vol . 10 No . 1 Agustus 2017 ISSN : 1979$8415,10(1), 37-47$.

Köse, U. (2010). A web based system for project-based learning activities in "web design and programming" course. Procedia - Social and Behavioral Sciences, 2(2), 1174-1184. https://doi.org/10.1016/j.sbspro.2010.03.1 68

Majore, G., \& Kepka, M. (2015). Taxonomy and Application of em for Functional Design of Web Map Applications. Procedia Computer Science, 77, 158-166. https://doi.org/10.1016/j.procs.2015.12.37 5

Malau, E., Salim, A., Santoso, B., \& Ramadan, R. (2018). Sistem Informasi Manajemen Perpustakaan Dengan Barcode Di GKI Gunung Sahari Jakarta, 5(1), 41-50.

Matausch, K., Peböck, B., \& Pühretmair, F. (2012). Accessible content generation an integral part of accessible web design. Procedia Computer Science, 14(Dsai), 274-282.

https://doi.org/10.1016/j.procs.2012.10.03 1

Mulayana, U., \& Gustina, D. (2016). Perancangan Sistem Informasi Penjualan Handphone Berbasis WEB pada Toko Ilham Cellular Jakarta. Jurnal Ilmiah FIFO, 8(2), 161-172.

Nedianto, A., \& Hakim, L. (2018). Aplikasi Administrasi Dan Pembelajaran Lembaga Bimbingan Belajar Wahid, S College Berbasis Web Mobile, 014(02), 63-69.

Nurmi, H. (2015). Membangun Website Sistem Informasi Dinas Pariwisata. Edik Informatika, 1, 1-6.

Piri, H. G. (2013). Kualitas Pelayanan Jasa 
Pengaruhnya terhadap Loyalitas Pelanggan pada Steiner Salon Manado. Jurnal EMBA, 1(4), 504-512.

Septa, R., Hamzah, A., \& Andayati, D. (2014). Sistem Informasi Pengolahan Data Ikpm (Ikatan Keluarga Pelajar Mahasiswa) Muara Enim Berbasis Web Menggunakan Php Dan My Sql. Jurnal SCRIPT, 2(1), 59-68. https://doi.org/Muh. Ibnu Habil Hanafi, Suwanto Raharjo, Suraya

Setyanto, A. (2010). Automatics Software Analisys, 11(3), 12-16.

Surya, I. (2017). Jurnal Teknologi dan Sistem Informasi Kebutuhan Perangkat Lunak Untuk Aplikasi Data Mining. Jurnal Teknologi Dan Sistem Informasi, 02, 233240. https://doi.org/10.25077/TEKNOSI

Yehendra, \& Yulianto, R. E. (2015). Rekayasa Perangkat Lunak Pengolahan Data Distribusi Obat- Obatan Di Pt . Anugrah Pharmindo Lestari Berbasis Web. Momentum, 17(2), 68-75.

Yuliana, R. (2012). Analisis Pengaruh Strategi Service Recovery Yang dilakukan Perbankan Terhadap Kepuasan Nasabah di Kota Semarang, 4(2), 39-52. 